\title{
MacchiariniGate: The Fall from Grace of Stem Cell Healer, Paolo Macchiarini, and Clues and Concerns from the Early Literature that Cast Ethical Doubts
}

\author{
Jaime A. Teixeira da Silva \\ P. O. Box 7, Miki-cho post office, Ikenobe 3011-2, Kagawa-ken, 761-0799, Japan; jaimetex@yahoo.com
}

\begin{abstract}
After a long and successful career in tracheal surgery and lung cancer, Paolo Macchiarini became very famous in 2008 with the transplantation of a trachea from a cadaver that then apparently used the patient's own stem cells to supposedly regenerate new trachea, i.e., tissue-engineered tracheae. Among the nine patients that received this revolutionary treatment, using biological or artificial tracheae, under Macchiarini's supervision, six have reportedly died. Although several critics had expressed concerns with the procedures, allegations of misconduct against Macchiarini first arose in August of 2014 by four Karolinska Institutet $(\mathrm{KI})$ colleagues, and an independent investigation was called for by $\mathrm{KI}$ based on claims made in seven published papers. Among the claims were the fact that the procedure constituted a high risk, information on the patients was incomplete and that there was no or incomplete ethical approval, thus constituting misconduct. His CV was also shown to contain inaccuracies. By September 10, 2016, most of these claims have now proved to be true, and Macchiarini was found guilty of misconduct by KI. This paper looks primarily at earlier published papers by Macchiarini and his collaborators in a search for clues to better understand the evolution of altruism, or narcissism. An assessment of the controversial papers, and of letters written by critics and skeptics like Pierre R. Delaere, indicate that insufficient experimental evidence was presented for several case studies, and that claims made about the success of the procedures exceeded what was shown by the evidence. A domino effect of personal and professional tragedies ensued, in rapid succession, between 2014 and 2016. The effect on the field of stem cell research has been chilling, and the side-effects have taken their toll, with several high-profile resignations, primarily at $\mathrm{KI}$, within the Swedish education system and in the Nobel Committee. This case has mesmerized the bioethics and biomedical communities for years.
\end{abstract}

Key words: ethics in medicine; Karolinska Institutet; legend; science; stem cell; tracheae

Paolo Macchiarini's experience and rationale: clues from the early literature: To understand how it is that a famed thoracic surgeon, Paolo Macchiarini, born in Basil, Switzerland, in 1958, and the child of Italian parents ${ }^{1}$, has become the center of one of the world's greatest stem cell research scandals, a look at the individual's publishing history could reveal clues as to how ideas and objectives may have evolved over time. Most stories that have more recently grabbed headlines over the past four years, from 2014-2018, either in the mainstream media, or on blogs, tended to focus on a very specific set of papers that later became the subject of an ethics investigation and a complex series of events that would eventually lead to the current downfallen status of Macchiarini. Most of those 
stories, however, do not appear to have examined the early Macchiarini literature in detail, in a search for clues that could allow the public and stem cell community to better understand how Macchiarini and colleagues could have reached this state of fall from grace. In this first section, I seek to find clues in earlier papers and the wider Macchiarini literature, in a bid to understand how things began to fall apart.

It is important to maintain this scandal in mind, because it may afflict any stem cell scientist that is left with their guard down, who has been careless, who has cut corners in an attempt to gain fame or reputation using less than accepted methods, or who has dappled in misconduct.

A search for Paolo Macchiarini on PubMed - the world's leading medical science data-base revealed, until 2016, 193 papers related primarily to thoracic surgery, lung cancer, and xenotransplantation, the latter which involves the transplantation of non-human cells, tissues or organs into humans. Macchiarini in 1998 described himself, in a three-person correspondence to Nature, while working at the Department of Thoracic and Vascular Surgery, Hôpital Marie-Lannelongue, Paris-Sud University in France, as "a clinician involved in clinical allotransplantation and experimental xenotransplantation (heart-lung and lung)"2. That 1998 letter to the editor, which was in fact a rebuttal to Butler et al., also published in the same year ${ }^{3}$, revealed some fundamental aspects of this thoracic surgeon that might later have led to his unravelling and consequent downfall. The Butler et al. paper in fact sounded an alarm on xenotransplantation, highlighting the risks involved, and claiming that there was insufficient scientific evidence to allay such fears, especially in the light of evolving regulation, particularly in the US where, at that time, the US Food and Drug Administration (FDA) had placed a moratorium on porcine transplants in the light of the fact that endogenous retroviruses found in pigs could infect human cells in vitro, a revelation made by Le Tissier et al. in $1997^{4}$, researchers at British institutes, of the so-called "Trojan pig". Butler et al. further injected fear into the unregulated use of xenotransplantation in surgeries in "xeno-havens", where experimental surgeries using xenotransplants and stem cells could take place under a business model that was waiting to explode to deal with surgeries dying to find solutions. In 1998, Macchiarini countered these concerns and fears by stating, in a direct personal jab at Butler et al. ${ }^{1:}$ "Although you have published quite a lot on this subject, as far as I know none of the authors has been at the bedside of a patient", suggesting that the emotive and subjective perspective took precedence over objective, evidence-based science. Further widening the rift with the stance by Butler et al., by claiming to understand the pain and struggle of patients, Macchiarini stated: "They [referring to Butler et al.] cannot feel the frustration of patients who die while waiting for an organ nor the wonderful sensation of being able once more to breathe or to move without effort. What about the parents seeking a therapeutic solution for children with terminal diseases? As a clinician, is it really ethical for me to have no solution or should I be more concerned with infection and social arguments?" This fascinating emotive appeal to patients' struggles - even if implicitly ignoring the scientific evidence or red flags - may have served as the apparently altruistic factor that would spur ensuing research into xenotransplantation and thoracic surgery by Macchiarini. In the same letter, Macchiarini describes the successful use of a "nude mouse to 
host a human trachea derived from human embryonic cells." Several months later, $10 \mathrm{~cm}^{3}$ of that human trachea was transplanted "into piglets to test whether the process might be used in human babies as an alternative to their death." Claiming success with this procedure, Macchiarini then challenged Butler et al.: "Do I have the right to propose this technique to the parents? I think I do and we are in the process of asking for permission to do it." With this seminal statement that challenged conservative protocol, Macchiarini positioned himself as being a surgeon with an altruistic objective aimed at aiding dying patients with life-saving remedies in the form of xenotransplants, even if these went against popular or cautionary rationale, or scientific evidence (e.g. ${ }^{4}$ ). Planting his exploratory flag into unchartered territory, Macchiarini ended his commentary by emphatically stating "The time has come for clinicians rather than basic researchers to give their opinions on clinical xenotransplantation", projecting thus himself and his research group, as a key solution to dying patients.

Why did Macchiarini make such bold and confident assertions when his own published findings of a pig-to-human xenograft, in which pig lungs were perfused with human blood, showed "an early and violent hyperacute rejection that results in irreversible pulmonary dysfunction and failure within approximately 150 minutes of reperfusion"5? Such failed xenografts, and other failed tracheal and tracheoesophageal allotransplantation experiments, which were made by The Paris-Sud University Lung Transplantation Group ${ }^{6,7}$, should have served as humbling experiences to indicate that the risks both violent and fatal - supported the concerns and warnings made by Butler et al. and should have served as risk-limiting factors in the search for supernatural solutions to human medical deficiencies. Close examination of the 1997 Macchiarini et al. paper $^{5}$ reveals that other than broad statements related to animal care and informed patient consent to use blood, no other ethical guidelines or approvals were indicated. Admittedly, at that time, it is likely that International Committee of Medical Journal Editors (ICMJE)-style requirements for animal-based tests or human trials - which have only in recent years become detailed and stringent for biomedical results to be published in biomedical journals - did not yet exist.

Failed procedures were no stranger to Macchiarini, as was shown by a paper detailing a failed tracheal allograft replacement ${ }^{8}$, a product of his $\mathrm{PhD}$ thesis. However, the attention to scientific discovery as the guiding force to find medical solutions to treatment and surgery seemed to have predominated Macchiarini's earlier work on lung cancer, for example in $1991^{9}$, apparently driven by sound scientific principles and patient-related ethics. So, at what point did Macchiarini deviate off the ethical path, or was it a gradual progression in a passionate desire to find a cure for respiratory ailments, but brought down by an incredible growth in power and global fame, and a concomitant increase in funding by European and Russian agencies?

Examination of Macchiarini's CV (http://www.circare.org/info/pm/CV eng.pdf) published by his (until recently) Swedish employer, the Karolinska Institutet $(\mathrm{KI})$, in Sweden, indicates some facts worthy of pointing out, as a background to the evolution of research in xenotransplantation that will support this evolution in stances and practice by Macchiarini that eventually led to his downfall. This CV, which was used to guarantee 
Macchiarini's position at $\mathrm{KI}$, specifically at the Karolinska University Hospital, was shown by $\mathrm{KI}$ on September 9, 2016 to carry inaccuracies.

Statements made in 2004 by Macchiarini ${ }^{10}$ suggest Macchiarini's frustration with the progress of science in finding innovative solutions to tracheal grafts or replacements, alluded to in the title as "déjà vu all over again", noting that "an ideal graft must have some prerequisites: lateral rigidity and longitudinal flexibility, complete air tightness, biocompatibility, nonimmunogenicity, nontoxicity, resistance to bacterial colonization, freedom from the need for immunosuppression, permanent construction, ease of implantation, and the ability to provide a platform of ciliated respiratory epithelium resurfacing." With this statement, the mental blue-print for how he would achieve his revolutionary xenotransplantation surgeries were set in stone.

The rise of Paolo Macchiarini to legendary status: Macchiarini's bold objectives appeared to thus have been set in stone by 2004 , at which point he moved from Hannover Medical School in Germany (1999-2004) to the University of Barcelona in Spain (2005-2009). The work conducted in Germany with the Hannover Interdisciplinary Intrathoracic Tumor Task Force Group and in Spain, together with his collaborators, would ultimately propel Macchiarini to legendary status. Was an invitation to speak on "Surgical management of the subglottic airway" at the Royal Bristol Infirmary, University of Bristol, UK, in November 12, 2001, as documents his $\mathrm{KI} \mathrm{CV}$, the stepping stone and start of what would be a highly productive and fame-inducing collaboration with the Martin Birchall group at the Division of Surgery, Department of Clinical Medicine, University of
Bristol? From 2009-2012, Macchiarini was an Honorary Professor of Surgery at University College London, suggesting that the Birchall alliance was rewarding. Independent of what the driving forces were that led to this powerful Germany-Spain-UK experience, by the time Macchiarini reached $\mathrm{KI}$ in Sweden, he had already clocked several dozen publications in some of the most respected and leading medical journals related primarily to xenotransplantation and surgery, including - but to name a few - the British Journal of Surgery ${ }^{11}$ of $\mathrm{JIF}_{2015}=5.596$, multiple papers in The Journal of Thoracic and Cardiovascular Surgery of $\mathrm{JIF}_{2015}=$ 3.494, Annals of Thoracic Surgery of $\mathrm{JIF}_{2015}=0.658$, Biomaterials of $\mathrm{JIF}_{2015}=8.387$, New England Journal of Medicine of $\mathrm{JIF}_{2015}=59.558^{12}$, and The Lancet of $\mathrm{JIF}_{2015}=44.002^{13}$. In fact, Macchiarini was no stranger to publishing prowess, scoring a paper in The Lancet in 1992 from work with his Italian collaborators at the University of Pisa on neovascularisation and metastasis in lung cancer ${ }^{14}$.

Of importance to the realization of Macchiarini's altruistic dreams, and to finally solidify his proof of success, serving as a counter-argument to the disagreements with Butler et al. ${ }^{3}$ that surfaced a decade earlier, several of those papers projected the stem cell-based tissue-engineering theory into practice, including with human trials, such as in five papers $^{13,15,16,17,18 .}$

\section{The Macchiarini turning point, or was the only} way up? Emboldened by increasingly challenging research, larger research groups, bigger funding and higher profile publications in leading medical journals, both as original research and reviews, Macchiarini was on track to global fame with tracheal transplants, until a rock was hit on the road 
to fame, a classic case of a boom-to-bust career caused by uncontrollable public scandal ${ }^{18}$. That rock, which may now be considered as one of several fatal boulders, refers to the 2008 paper in The Lancet $^{2}$. From that paper, a 2009 erratum emerged in which it was found that the affiliations of three of the authors were incorrect. In November 2008, while praising the experiment in the 2008 paper $^{2}$, Sato and Nakamura ${ }^{19}$ also expressed reservations about the mechanism underlying its success, stating that "Macchiarini and colleagues did not use any specific measures to aid revascularisation in the graft. Nevertheless, they observed rapid recovery of blood flow and luminal mucosal appearance. The seeded epithelial cells and chondrocytes in the biological prosthesis before the implantation may have induced early revascularisation. However, as the investigators mention, it is unclear whether the seeded cells regenerated the tissue, including the cartilage and mucosa. Until the functions of the seeded cells are more clearly elucidated, some doubt remains about whether their results should be regarded as a fully tissue-engineered replacement or an allotransplantation of the trachea."

Despite this, almost mesmerized by the almost magical discovery, a reporter from a British newspaper, The Independent (http://www.independent.co.uk/us), Jeremy Laurance, wrote a commentary for The Lancet using hyperbolic praises, such as: "Every superlative in the book from an "astonishing milestone" to "the start of a new era in medicine" has been used to describe the first successful windpipe transplant", "unquestionably a major development", "On a scientific level, the procedure has proved that it is possible to grow organs using a patient's own stem cells, eliminating the problems of rejection that have always plagued transplants. Stem-cell research, which has promised so much in the laboratory, has at last delivered a genuine clinical advance"20. The Macchiarini-Birchall alliance, which started in 1997, and everyone in between, had finally received dividends from its investments, a medical discovery almost too good to be true. The Lancet page indicates that, to date, that paper had been cited 778 times on Scopus until the end of 2016.

Institutional review board and ethics permissions: Yet, statements made by Birchall in the Laurance piece may have proved to be the fateful blow and the beginning of the end to Macchiarini's rise to fame: "Ethical permission was obtained - which would not have been possible in the time in the UK, according to Birchall — and the team got the go-ahead. A donor trachea was obtained and stripped of its living cells using a process developed at the University of Padua. Stem cells from Castillo's bone marrow and airway were taken to the Faculty of Clinical Medicine and Dentistry, University of Bristol, and grown following a protocol developed by Anthony Hollander. There was even a moment when the project teetered on the verge of disaster as easyJet refused to allow the cells on board its flight. Then a medical student remembered a German physician with a plane who agreed to fly the cells to Barcelona, where they were placed with the trachea in a bioreactor developed in Milan and, 4 days later, the seeded trachea was transplanted." This paragraph, even to non-medical scientists, reeks of questionable ethics: if it was impossible to obtain ethical permission for such a procedure in the UK at the time, then how was it possible to complete the procedure at the University of Bristol in the UK? Clues to this question later emerged in a 2012 paper by Lowdell et al. ${ }^{21}$, as 
described later. Why did EasyJet refuse to carry these cells? Who was this elusive German physician who transported the cells? And most importantly, was there proof at all, from any of the researchers' research institutes, of ethical approval for this procedure? Ironically, Birchall stated to Laurance: "We, Paolo and I, took the biggest personal risk. We could have been in serious trouble if things had gone wrong-fingers would have been pointed." These issues remain unclarified, and an investigation into Birchall's decisions and level of responsibility in the Macchiarini-Birchall alliance have yet to be explored and resolved.

Global criticism of the Macchiarini et al. (2008) paper: Coincidentally, or not, three letters to The Lancet were published in February 2009, by Wu et al., of the School of Stomatology, Fourth Military Medical University, Xi'an, in China, by Delaere and Hermans, of the Department of Otolaryngology Head \& Neck Surgery and the Department of Radiology, respectively of the University Hospital, Catholic University of Leuven, Belgium, and by Zhang et al., collectively from the Department of Orthopaedics, Second Affiliated Hospital of Zhejiang University School of Medicine, in Hangzhou, China, and the Tissue Engineering Centre, Shanghai 9th People's Hospital, Shanghai Jiaotong University School of Medicine, in Shanghai, China. The most pertinent criticisms made of the 2008 Macchiarini et al. paper, and whose process is described by Wu et al. ${ }^{22}$ as "Macchiarini and colleagues then used this tubular matrix [referring to "a nature-derived tracheal matrix from donor tracheal tissues"] as a scaffold on which to engineer native tracheal tissues by seeding autologous epithelial cells and mesenchymal stem cells.", by these three groups were:

"Macchiarini and colleagues do not indicate whether this tracheal matrix would eventually be replaced by newly formed cartilage tissues. Such a decellularised matrix would degrade completely in vivo, and would lose its original supporting role, which would lead to the collapse of the airway. We suggest detailed follow-up of morphological changes to the patient's trachea"22.

"Macchiarini and colleagues seeded cells with a density of $1.0 \times 10^{6} / \mathrm{mL}$ onto the surface of the scaffold. For cartilage tissue engineering, the preferred cell density is $5.0 \times 10^{7} / \mathrm{mL}$, because of chondrocytes' limited proliferate and migrating ability in vivo. In this study, how many cells could penetrate into the pores of the scaffold, and could the above cell density provide sufficient cells for further tissue formation? Perhaps such data could be presented in in-vitro specimens" 22 .

"Although revascularisation has been noticed in the inner surface of the graft, we think it will be difficult for the seeded epithelial cells to survive and form mucosal tissue at this site, because of the length of time full revascularisation will take and of the very limited nutritional perfusion from surrounding tissues. We suggest that Macchiarini and colleagues could collect the patient's sputum postoperatively and analyse the cells in it so that we can ascertain whether the seeded epithelial cells have been chipped out and discharged" 22 .

"The main drawback of the proposed reconstruction is the lack of an intrinsic blood supply"23. "Histological analysis of the full thickness of the cartilaginous and membranous tracheal construct at 
the time of implantation would have allowed for a comparison of the transplant histology with that of the normal tracheal wall. The paper's illustrations show only isolated and non-organised clusters of epithelial and cartilage cells, and do not allow for histological comparisons"23. "The volume-rendered CT images and virtual bronchoscopic images ... provide no clear information about the reconstructive value of the tissue-engineered tracheal transplant." 23 "The reconstructive value of the avascular tissue-engineered transplant remains unclear in the absence of information about preimplantation histology and postreconstruction morphology"23.

"One point was not discussed"; "what would Macchiarini and colleagues have done if, having prepared the tissue-engineered graft, the patient's condition was found to be unsuitable for transplantation at that time?"; "although Macchiarini and colleagues' result is very exciting, perfection of graft preservation might ultimately do more to further the clinical application of tissue-engineered products"24.

Almost ironically, what had given the appearance of a magical, perfect treatment to treat trachea-bronchial problems, suddenly appeared to have a series of defects and insufficient proof to support the stated claims. In their 2009 response, Macchiarini et al. ${ }^{25}$ rebutted all three sets of readers' concerns, while stating: "Although there are many important scientific questions to be addressed, including those raised by our correspondents, we argue that clinical outcomes are far more important in assessing the value of the technique than pre implantation histology." What was curious about the authors' response was that it was co-authored by only five of the 15 original authors. Were the remaining 10 co-authors consulted, and had they approved this response on their behalf? No public explanation exists for this discrepancy in authorship.

Refutation of criticism by Macchiarini and colleagues: The patient in the 2008 paper $^{13}$ is still alive, a fact that Macchiarini et al. could use to argue the fact that their experiment was a success. In 2011, Jungebluth et al. ${ }^{26}$, with Macchiarini as the last, senior author, and who was already associated with $\mathrm{KI}$ in Sweden at that time, a new case was presented as part of this collaboration between Sweden, Iceland, Germany and the UK. The authors reported, in a 36-year-old male patient, a "clinical transplantation of the tracheobronchial airway in a patient with recurrent primary trachea cancer, with use of a tailor-made artificial scaffold reseeded ex vivo with mononuclear cells (MNCs) and a growth factor-induced endogenous stem cells mobilisation." The deviation of the technique from the 2008 paper was rationalized and explained as follows: "In 2008, we reported the first fully tissue-engineered tracheal transplantation with a non-immunogenic decellularised human donor trachea reseeded with bone-marrow-derived mesenchymal stem cells (MSCs) and respiratory cells. However, this approach is limited by the shortage of donor organs of an appropriate size and has other disadvantages ... As a result, an alternative, tailor-made synthetic tracheal scaffold is an urgent clinical need." Soon after, a study published in The Lancet by Birchall in a UK-exclusive collaborative effort, and excluding Macchiarini, reported on the "replacement of an adult airway using stem cells on a biological scaffold", i.e., a stem-cell-based organ transplant, in a 12 -year-old boy ${ }^{27}$. The study concluded by stating: 
"At 2 years follow-up, he had a functional airway and had returned to school." At first sight, three successful studies, with three The Lancet publications and a massive spike in research funding would spell apparent glorious success. Yet, this was not to be.

In an interview with David Holmes ${ }^{1}$ regarding the Jungebluth et al. study ${ }^{26}$, which Holmes described as "the world's first transplant of a trachea made entirely from a synthetic nano-composite scaffold, seeded with the recipient's own stem cells", Macchiarini stated "I'm like a wild animal that does not need to be in a cage, I need to express my convictions that I can help a patient with innovative things." He also stated that "only those who risk going too far can possibly find out how far one can go." In the same interview with Holmes, Philipp Jungebluth, who at that time already had an 11-year relationship with Macchiarini, noted: "Crossing frontiers is the only way to develop medicine and research further. Paolo crossed them already and changed medicine, and he will keep on going." This was also a fateful prediction. Teaming up with a team of heavy hitters in the world of medicine in the US, Macchiarini indicate that "biological scaffolds made of allogeneic or xenogeneic extracellular matrix derived from nonautologous sources. These scaffolds can act as an inductive template for functional tissue and organ reconstruction after recellularisation with autologous stem cells or differentiated cells." and that, when "guided by appropriate scientific and ethical oversight, could serve as a platform for the engineering of whole organs and other tissues"28. In a personal email to the author in September 2016, Badylak would come to distance himself from Macchiarini.
In a 2013 paper $^{29}$ that includes an interview with Macchiarini and Birchall, as well as the opinions of critics such as Delaere, Vogel stated that in addition to the 2008 case, another 14 patients had received bioengineered tracheas, by either the Macchiarini or the Birchall group. Raising great concerns in that piece, Vogel stated that "The researchers have mentioned other patients in passing in several papers, but no formal reports have been published about their health, and Science has not been able to independently verify the current status of all the patients." In the Vogel paper, it became evident that at least two of the patients had died, but a 2016 report indicated that 6 out of 9 patients had deceased $^{30}$ while the reporting by a science watchdog ${ }^{31}$, Leonid Schneider, indicates that many more patients exist, although their deceased status is unclear ${ }^{32}$. It is unclear if there are other patients. Birchall claimed that one of the children died of the cancer while Macchiarini indicated that "another adult patient also died of the cancer that had damaged the trachea." Consistent with other criticisms of the Macchiarini and Birchall findings, Delaere affirmed that "If they claim something miraculous, they have to show corresponding data. They don't do that." Almost coincidentally, Gonfiotti et al. $^{33}$ showed how the 2008 patient, despite requiring repeated endoluminal stenting, was able to sustain a relatively normal social and working lifestyle, five years after the original transplant.

In 2013, Birchall et al. ${ }^{34}$, excluding Macchiarini, offered a rebuttal, indicating that all three projects were different, independent, but "congruent", and as an "evolution in thought". Stressing that clinical trials are need to support their one-off case reports, Birchall et al. further defended their studies by indicating that the treatments differed for different 
patients, but that all were "treated under compassionate use-licences", referring to the use of a highly controversial approach in which "Advanced therapy medicinal products (ATMPs) are substantially modified human or animal cells or cell-device combinations" used to treat patients outside of a clinical trial ${ }^{21}$. Birchall et al. close their rebuttal by stating that "There will probably always be a need for the compassionate use of evolving techniques. Such uses provide not only hope for an individual, but useful clues to inform the necessary laboratory science." In essence, the Macchiarini et al. ${ }^{25}$ and Birchall et al. ${ }^{34}$ rebuttals failed to offer concrete responses to scientific concerns, preferring instead to offer broad excuses, the "evolving" and "compassionate" arguments, and little substance to explain the observed medical shortcomings.

Until mid-2014, it would have felt that Macchiarini and colleagues were still on track to increased fame, until tragedy after tragedy struck. The saga as continues to unfold from 2014-2018, is summarized by Kremer ${ }^{30}$, Retraction Watch ${ }^{35}$, with alternative perspectives by Schneider ${ }^{36}$, who is being sued by Macchiarini. A formal report issued to $\mathrm{KI}$ on September 23, 2016 37 , sheds new light on possible ethical figure-related issues with Macchiarini-related papers. This will surely not be the last we hear of MacchiariniGate.

Conclusions and take-home message: The last few years has seen first large praise towards the Macchiarini (and to a less extent Birchall) successes with transplantations. Those studies were astonishing at the time, in a positive way, because they offered the hope and promise of real solutions to near-dying patients. Yet, it took so many years for specialists and scientists to notice the warning signs, many of which had even been fairly clear in published papers and editorials. Apart from a handful or less of outspoken critics, undoubtedly Delaere being the most vocal, the astonishing aspect of MacchiariniGate is how many elite journals, their editor boards, including editors-in-chief, and hundreds of scientists who cited these papers, failed to notice any irregularities. There was clearly a culture of suppressed opinion at $\mathrm{KI}$, as several co-authors of a 2011 Jungebluth et al. paper $^{38}$ only requested to be removed as co-authors in March and April 2016 after several ethical investigations had been initiated, two ethical reports had been issued and several negatively revealing documentaries were aired on Swedish television. MacchiariniGate shows that hyperbolic claims of magnificent and almost miraculous results should always be assessed with great caution and additional scrutiny. There is no doubt that the desire to publish a revolutionary medical finding may have also prompted insufficient scrutiny by The Lancet and other top level leading medical journals, as they sought the top publishing prize for bringing these "revolutionary" results to the medical and stem cell research communities. Although it is still unclear if Macchiarini himself is in charge of all of the ethical mishaps underlying these cases, two salient points remain: a) regarding the published papers, all authors assume collective responsibility when something is published, so they receive glory when the papers were lauded, but they must also assume collective responsibility should those papers be felled due to ethical oversight or misconduct; b) amidst the multiple co-authors, many young surgeons, medical practitioners and researchers will undoubtedly be - where in fact misconduct has taken place - be the innocent victims of another person's lack of respect of research and publishing 
protocol and ethics. This case must therefore serve to fortify current checks and balances in research laboratories, with oversight by research institutional ethics committees, or even national independent ethical boards, greater scrutiny and a desire to slow down the publishing process to ensure more quality control and checks. As shown by the Obokata STAP stem cell scandal and now MacchiariniGate, there are risks to one's career, and even to human life, as one seeks for research objectives with grand solutions. These aspects, together with six core ethical issues (1. ethical guidelines and laws for high-risk ethical procedures, transplantation and clinical trials; 2 . the value and weight of "ethical guidelines"; 3. plagiarism, self-plagiarism and professional victimization; 4. ethical inconsistencies by the editor-in-chief of Elsevier's The Lancet's Richard Horton; 5. the need to show ethical consent forms as part of the open data debate; 6 . The ethics of a factually inaccurate and outdated $\mathrm{CV}$ ) discussed elsewhere ${ }^{39}$ merit greater open discussion by the biomedical community. Six Macchiarini papers are destined for retraction following an investigation by the Central Ethics Review Board ${ }^{40}$. Finally, the issue of brand protection in the Macchiarini case ${ }^{41}$, despite wide-spread evidence over many years, is a new issue worthy of debate in biomedical ethics.

\section{References:}

1. Holmes D. Paolo Macchiarini: crossing frontiers. The Lancet 2012; 379(9819): 886.

2. Macchiarini P. Xenotransplants: proceed with caution. Nature 1998; 392: 11-12.

3. Butler D, Wadman M, Lehrman S, Schiermeier Q. Last chance to stop and think on risks of xenotransplants.

Nature 1998; 391: 320-324.
4. Le Tissier P, Stoye JP, Takeuchi Y, Patience C, Weiss

RA. Two sets of human-tropic pig retrovirus. Nature 1997; 389: 681-682.

5. Macchiarini P, Mazmanian GM, Oriol R, de Montpreville V, Dulmet E, Fattal S, Libert JM, Doubine S, Nochy D, Rieben R, Dartevelle P. Ex vivo lung model of pig-to-human hyperacute xenograft rejection. Journal of Thoracic and Cardiovascular Surgery 1997; 114(3): 315-325.

6. Macchiarini P, Mazmanian GM, de Montpréville VT, Dulmet EM, Chapelier AL, Dartevelle PG. Maximal preservation time of tracheal allografts. The Paris-Sud University Lung Transplantation Group. Annals of Thoracic Surgery 1995; 60(6): 1597-1604.

7. Macchiarini P, Mazmanian GM, de Montpréville VT, Dulmet EM, Chapelier AL, Dartevelle PG. Experimental tracheal and tracheoesophageal allotransplantation. Journal of Thoracic and Cardiovascular Surgery 1995; 110 (4, Part 1): 1037-1046.

8. Lenot B, Macchiarini P, Dulmet E, Weiss M, Dartevelle

P. Tracheal allograft replacement: an unsuccessful method. European Journal of Cardio-Thoracic Surgery 1993; 7:648-652.

9. Macchiarini P, Hardin M, Basolo F, Bruno J, Chella A, Angeletti CA. Surgery plus adjuvant chemotherapy for T1-3N0M0 small-cell lung cancer. Rationale for current approach. American Journal of Clinical Oncology 1991; 14(3): 218-224.

10. Macchiarini $P$. Trachea-guided generation: déjà vu all over again? The Journal of Thoracic and Cardiovascular Surgery $2004 ; 128(1):$ 14-16.

11. Birchall MA, Bailey M, Barker EM, Rothkotter HJ, Otto K, Macchiarini P. Model for experimental revascularized laryngeal allotransplantation. British Journal of Surgery 2002; 89: 1470-1476.

12. Lotz J, Macchiarini P. Double aortich arch: diagnosis by MRI. New England Journal of Medicine 2004; 25:351(22): e20. 
13. Macchiarini $P$, Jungebluth $P$, Go $T$, Asnaghi MA, Rees

LE, Cogan TA, Dodson A, Martorell J, Bellini S, Parnigotto PP, Dickinson SC, Hollander AP, Mantero S, Conconi MT, Birchall MA. Clinical transplantation of a tissue-engineered airway. The Lancet 2008; 372(9655): 2023-2030. Erratum: The Lancet 2008; 373(9662): 462. 14. Macchiarini $P$, Fontanini $G$, Squartini $F$, Angeletti $C A$, Hardin MJ. Relation of neovascularisation to metastasis of non-small-cell lung cancer. The Lancet 1992; 340(8812): $145-146$

15. Asnaghi MA, Jungebluth $P$, Raimondi MT, Dickinson

SC, Rees LE, Go T, Cogan TA, Dodson A, Parnigotto PP, Hollander AP, Birchall MA, Conconi MT, Macchiarini P, Mantero S. A double-chamber rotating bioreactor for the development of tissue-engineered hollow organs: From concept to clinical trial. Biomaterials 2009; 29: 5260-5269. 16. Baiguera S, Jungebluth $P$, Burns A, Mavilia C, De Coppi P, Macchiarini P. Tissue engineered human tracheas for in vivo implantation. Biomaterials 2010; 31 : 8931-8938.

17. Baiguera S, Gonfiotti A, Jaus M, Comin C, Paglierani M, Del Gaudio C, Bianco A, Ribatti D, Macchiarini P. Development of a bioengineered human larynx. Biomaterials 2011; 32(19): 4433-4442.

18. Teixeira da Silva JA, Dobránszki J, Al-Khatib A. Legends in science: from boom to bust. Publishing Research Quarterly 2016; 32(4): 313-318.

19. Sato T, Nakamura N. Tissue-engineered airway replacement. The Lancet 2008; 372(9655): 2003-2004. 20. Laurance J. Martin Birchall: using stem cells to help make transplant history. The Lancet 2008; 372(9656): 2104.

21. Lowdell MW, Birchall M, Thrasher AJ. Use of compassionate-case ATMP in preclinical data for clinical trial applications. The Lancet 2012; 379(9834): 2341.

22. Wu W, Liu Y-P, Zhao Y-M. Clinical transplantation of a tissue-engineered airway. The Lancet 2009; 373(9665): 717.
23. Delaere PR, Hermans R. Clinical transplantation of a tissue-engineered airway. The Lancet 2009; 373(9665): 717-718.

24. Zhang $\mathrm{P}$, Luo X-S, Wang H-J. Clinical transplantation of a tissue-engineered airway. The Lancet 2009;

373(9665): 718.

25. Macchiarini P, Birchall MA, Hollander AP, Mantero S, Conconi MT. Clinical transplantation of a tissue-engineered airway - authors' reply. The Lancet 2009; 373(9665): 718-719.

26. Jungebluth $P$, Alici E, Baiguera $S$, Blomberg $P$, Bozóky B, Crowley C, Einarsson O, Gudbjartsson T, Le Guyader S, Henriksson G, Hermanson O, Juto JE, Leidner B, Lilja T, Liska J, Luedde T, Lundin V, Moll G, Roderburg C, Strömblad S, Sutlu T, Watz E, Seifalian A, Macchiarini P. Tracheobronchial transplantation with a stem-cell-seeded bioartificial nanocomposite: a proof-of-concept study. The Lancet 2011; 378(9808): 1997-2004. Erratum: The Lancet 2016 Mar 5; 387(10022): 944, removing Karl-Henrik Grinnemo. Erratum: The Lancet 2016 Mar 26; 387(10025): 1276. Erratum: The Lancet 2016 Apr 2; 387(10026): 1376, removing Bo Nilsson, Katarina Le Blanc, and Ana Isabel Teixeira. Expression of concern: The Lancet 2016 April 2; 387(10026): 1359.

27. Elliott MJ, De Coppi P, Speggiorin S, Roebuck D, Butler CR, Samuel E, Crowley C, McLaren C, Fierens A, Vondrys D, Cochrane L, Jephson C, Janes S, Beaumont NJ, Cogan T, Bader A, Seifalian AM, Hsuan JJ, Lowdell MW, Birchall MA. Stem-cell-based, tissue engineered tracheal replacement in a child: a 2-year follow-up study. The Lancet 2012; 380(9846): 994-1000.

28. Badylak SF, Weiss DJ, Caplan A, Macchiarini P. Engineered whole organs and complex tissues. The Lancet 2012; 379(9819): 943-952.

29. Vogel G. Trachea transplants test the limits. Science 2013; 340(6130): 266-268. 
30. Kremer W. Paolo Macchiarini: A surgeon's downfall. http://www.bbc.com/news/magazine-37311038 (2016; last accessed: June 21, 2018)

31. Teixeira da Silva JA. Science watchdogs. Academic Journal of Interdisciplinary Studies 2016; 5(3): 13-15.

32. Schneider L. Macchiarini's trachea transplant patients: the full list.

https://forbetterscience.com/2017/06/16/macchiarinis-trac hea-transplant-patients-the-full-list/ (2017; last accessed:

June 21, 2018)

33. Gonfiotti A, Jaus MO, Barale D, Baiguera S, Comin C, Lavorini F, Fontana G, Sibila O, Rombolà G, Jungebluth $P$, Macchiarini $P$. The first tissue-engineered airway transplantation: 5-year follow-up results. The Lancet 2014; 383(9913): 238-44.

34. Birchall MA, Elliott MJ, Lowdell M, De Coppi P. Stem-cell-based, tissue-engineered tracheal replacement in a child - authors' reply. The Lancet 2013; 381(9861):

113.

35. Retraction Watch. Paolo Macchiarini. http://retractionwatch.com/category/by-author/paolo-macc hiarini/ (last accessed: June 21, 2018)

36. Schneider L. Macchiarini. https://forbetterscience.wordpress.com/?s=macchiarini (last accessed: June 21, 2018)

37. Teixeira da Silva, J.A. (2016) Report \#1 (18 cases) on Paolo Macchiarini-related papers and request for ethical investigation by Karolinska Institutet and Swedish authorities. Self-published 39 pages.

https://www.researchgate.net/publication/308475863 (last accessed: June 21, 2018)

38. Jungebluth $P$, Luedde $M$, Ferrer $E$, Luedde $T$, Vucur $M$, Peinado VI, Go T, Schreiber C, Richthofen MV, Bader A, Haag J, Darsow KH, Bartel SJ, Lange HA, Furlani D, Steinhoff G, Macchiarini P. Mesenchymal stem cells restore lung function by recruiting resident and non-resident proteins. Cell Transplantation 2011; 20(10): 1561-1574.

39. Teixeira da Silva JA. Ethical perspectives and ramifications to the Paolo Macchiarini case. Indian Journal of Medical Ethics 2017; 2(4): 270-275.

40. Schneider L. Swedish Central Ethics Review Board finds Macchiarini guilty of misconduct, requests retraction of 6 papers.

https://forbetterscience.com/2017/10/30/swedish-centralethics-review-board-finds-macchiarini-guilty-of-misconduc t-requests-retraction-of-6-papers/ (last accessed: June 21, 2018)

41. Berggren C, Karabag SF. Scientific misconduct at an elite medical institute: The role of competing institutional logics and fragmented control. Research Policy 2018 (in press) https://doi.org/10.1016/j.respol.2018.03.020

Author contribution statement: The author researched, wrote, and edited all versions of the manuscript.

Conflicts of interest and disclaimer: The author declares no conflicts of interest, financial or other. This research was conducted in the absence of any financial funding. The author has been in contact with Prof. Macchiarini and his co-authors, the journal editors and the Swedish authorities (KI and other), as well as media representatives, primarily between September 12 and 23, 2016, to deliver the reports indicated in $2016^{37}$. None of these contacts has influenced the content or outcome of the perspectives outlined in this commentary, which was submitted prior to the first contacts. 